\title{
CONFLITOS SOCIOAMBIENTAIS EM UNIDADES DE CONSERVAÇÃO EM ÁREAS URBANAS: O CASO DO PARQUE TIZO EM SÃO PAULO
}

\author{
P. A. ARCE ${ }^{1}$, C. J. S. PENDLOSKI, R. B. OLIVEIRA, A. L. C. F. GALLARDO, M. S. RUIZ \\ Universidade Nove de Julho - UNINOVE \\ paulina_arce@biologa.bio.br ${ }^{1}$
}

Artigo submetido em outubro/2013 e aceito em março/2014

\section{RESUMO}

Parques urbanos são importantes unidades de conservação reconhecidas como indutores de desenvolvimento sustentável nas cidades. No entanto, a criação e implantação desses parques deflagram vários conflitos socioambientais devido aos diversos interesses sobre a área a ser protegida, principalmente a questão do uso da terra e seus aspectos econômicos e sociais. Este artigo analisa o histórico dos conflitos que ocorreram na criação do Parque Tizo, em São Paulo, pela análise da configuração dos conflitos socioambientais e do papel do ministério público como facilitador do diálogo para sua negociação. $\mathrm{O}$ artigo demonstra que a implantação do Parque Tizo configurou uma situação complexa, com embate entre a parcela da população que tencionava promover a proteção de fragmentos de floresta remanescentes nas cidades e a outra parte, que vislumbrava ocupar e usufruir dessa área para subsistência, em função de alegados direitos de propriedade da terra.

PALAVRAS-CHAVE: Conflitos socioambientais, parques urbanos, problemas fundiários.

\section{SOCIAL AND ENVIRONMENTAL CONFLICTS IN PROTECTED LANDSCAPES OF URBAN AREAS: AN ANALYSIS FOCUSING ON THE TIZO PARK IN SÃO PAULO CITY, BRAZIL}

\begin{abstract}
Urban parks are important protected landscapes recognized as drivers for sustainable development in urban environment. However, the creation and deployment of these parks create many environmental conflicts due to a number of concerns on the area to be protected, especially regarding the economic and social aspects of the land use. This article analyzes the history of the struggles that happened during the creation of the Tizo Park, São Paulo state, through the exam of the
\end{abstract}

socioenvironmental conflicts configuration and the role of the Public Ministry as a facilitator for the negotiation dialogue. This article shows that the implementation of the Tizo Park turned out to be a complex situation, with a clash between the portion of the population that intended to protect the remaining forest fragments in the city and another party, which wanted to occupy and profit from this area to subsist, motivated by alleged land owning rights.

KEYWORDS: Environmental conflict, urban parks, land problems. 


\section{INTRODUÇÃO}

A degradação da paisagem e os impactos ambientais negativos gerados por ações antrópicas sobre os ecossistemas naturais resultam em uma situação de baixa qualidade ambiental para a população humana (SIMON, 2004).

A percepção de que o atual estilo de vida da humanidade conduz a essa condição impulsiona a sensibilização da sociedade sobre a importância da conservação dos fragmentos florestais que ainda restam no planeta.

Nesse sentido, a sociedade vem se organizando para exigir do Poder Público políticas de conservação e de proteção à fauna e flora (FERREIRA et al., 2001).

No Brasil, esse conjunto de políticas públicas está agregado no Sistema Nacional de Unidades de Conservação da Natureza (SNUC), instituído pela Lei Federal n.o 9985/2000, que objetiva a proteção dos recursos naturais em unidades de conservação (GUERRA, 2005).

O gerenciamento dessas unidades geralmente resulta em conflitos socioambientais, uma vez que diversos atores com interesses variados defendem lógicas distintas para gestão de bens de uso coletivo (BRITO, 2008).

No Estado de São Paulo, as áreas legalmente protegidas estão submetidas a forte pressão da urbanização que cada vez requer extensões de terras de grande expressão para abrigar e atender às necessidades de contingente populacional crescente. É do Poder Público a atribuição, com amparo de instrumentos legais, da gestão dessas unidades de conservação. Essa soberania não garante gerenciamento eficaz desses espaços de proteção ambiental e tampouco alcança inibir a deflagração de conflitos socioambientais.

Desse modo, estabelece-se como pergunta orientadora desta pesquisa: como conflitos socioambientais podem ser deflagrados durante a criação de unidade de conservação em área urbana?

Este artigo analisa os conflitos socioambientais que ocorrem na unidade de conservação, que abrange cinco municípios da Região Metropolitana de São Paulo (Osasco, Cotia, Taboão da Serra, Embu das Artes e São Paulo), denominada Parque Urbano de Conservação Ambiental e de Lazer "Parque Tizo" (Terras Institucionais da Zona Oeste), mais conhecida como Parque Tizo. Esse parque foi criado pelo Decreto Estadual no 50.597 de 27 de março de 2006, e destinado à administração da Secretaria de Meio Ambiente do Estado de São Paulo pelo Decreto Estadual no 57.458/11 (SÃO PAULO, 2006a; SÃO PAULO, 2011).

Para a consecução deste objetivo, analisou-se o envolvimento dos atores na implantação do parque, os conflitos gerados e a forma como foram gerenciados, bem como os impactos ambientais da implantação sobre ecossistema do parque.

\section{PROCEDIMENTOS METODOLÓGICOS}

Este trabalho foi desenvolvido com base em pesquisa qualitativa exploratória fundamentada em estudo de caso. Enquanto técnicas de coleta de evidências para a consecução 
do estudo de caso foram utilizadas revisão bibliográfica, pesquisa documental e entrevista não estruturada.

A pesquisa documental foi efetuada junto à Secretaria do Meio Ambiente do Estado de São Paulo para obtenção de informações sobre a criação e implantação do parque, os conflitos gerados durante a sua implantação, e os impactos ambientais que afetaram o ecossistema do parque. A entrevista não estruturada com o Promotor de Justiça Dr. José Eduardo Ismael Lutti, da Promotoria de Meio Ambiente do Ministério Público do Estado de São Paulo, teve como finalidade coletar informações sobre o papel do Ministério Público na resolução desses conflitos. A pesquisa bibliográfica, por meio de revisão de publicações, teve como objetivo fornecer uma plataforma teórica para análise do objeto proposto.

\section{TRABALHOS ANTERIORES}

Unidade de Conservação (UC) é uma tipologia inserida num conceito mais amplo de espaços territoriais especialmente protegidos previstas pela Constituição Federal Brasileira.

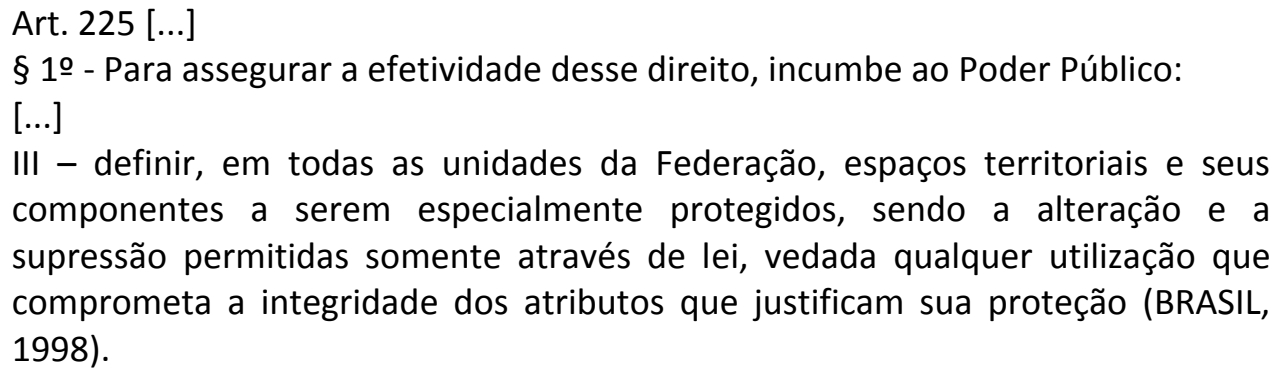
supressão permitidas somente através de lei, vedada qualquer utilização que comprometa a integridade dos atributos que justificam sua proteção (BRASIL, 1998).

Muito embora a doutrina defenda que o primeiro espaço especialmente protegido criado no Brasil tenha sido o parque Nacional de Itatiaia, em 1937, foi na verdade o Parque Estadual Alberto Loefgren (Horto Florestal), em 1896.

Recentemente, nota-se o esforço legislativo com o objetivo de padronizar o regime de proteção do complexo universo dessas áreas que foram sendo criadas ao longo dos anos pelos diferentes entes federados. Em 2000, foi editada a Lei Federal no 9.985 (BRASIL, 2000), que instituiu o Sistema Nacional de Unidade de Conservação da Natureza (SNUC), composto por doze categorias de unidade de conservação divididas em dois grupos: Proteção Integral e de Uso Sustentável. Essa lei visa contribuir para a manutenção da biodiversidade e dos recursos genéticos, proteger e recuperar recursos hídricos, recuperar ecossistemas degradados, proporcionar meios e incentivos para atividades de pesquisa científica e promover a educação ambiental, além da recreação (GUERRA, 2005).

Segundo Velasquez (2008), já foram criadas mais de 850 unidades de conservação que hoje integram o Sistema Nacional de Unidades de Conservação (SNUC).

No âmbito nacional, o SNUC tem no Conselho Nacional do Meio Ambiente (CONAMA) o órgão consultivo e deliberativo, e o Instituto Brasileiro do Meio Ambiente e dos Recursos Naturais (IBAMA) e o recém-criado Instituto Chico Mendes, seus órgãos de execução. Os órgãos estaduais e municipais de meio ambiente têm a função de implementar o SNUC em suas respectivas esferas de atuação, subsidiando as propostas de criação e administração das Unidades de Conservação (VELASQUEZ, 2008). 
Mesmo com todo o arcabouço jurídico de proteção às áreas de interesse ambiental e o envolvimento de órgãos das três esferas do Poder Público (federal, estadual e municipal), alguns desafios dificultam a implantação das unidades de conservação, como a falta de investimentos e o difícil gerenciamento destas unidades, que carecem de mais mecanismos e instrumentos legais.

O artigo 30, da Lei $n=9.985 / 00$, regulamentado pelo Decreto $\mathrm{n}-4.340 / 02$, previu a possibilidade de gestão compartilhada das UCs por meio de Termo de Parceria firmado pelo Órgão Executor da Unidade com Organizações da Sociedade Civil de Interesse Público (OSCIPs), selecionadas com observância da Lei de Licitações Públicas (BRASIL 2000).

Nesse sentido, o Estado de São Paulo saiu à frente dos demais estados com a aprovação do Decreto Estadual 48766/2004, no qual institui o Programa de Gestão Compartilhada, onde o governo estabelece parcerias com OSCIPs com essa finalidade (VELASQUEZ, 2008). Outro instrumento idealizado para organizar essas áreas protegidas consiste no Decreto Estadual 51.453/2006, que institui o Sistema Estadual de Florestas (SIEFLOR) composto pelas unidades de conservação da natureza e de produção florestal (INSTITUTO FLORESTAL, 2012).

Atualmente, as áreas protegidas no estado de São Paulo correspondem a 4,7 milhões de hectares e os parques estaduais inseridos em ambientes de expansão urbana somam cerca de 50 unidades. Essas áreas são consideradas espaços vulneráveis com relação à proteção de sua base natural, uma vez que a expansão das atividades humanas, principalmente o uso e ocupação do solo, exercem uma grande pressão sob esses espaços gerando conflitos socioambientais (INSTITUTO FLORESTAL, 2012).

Os conflitos relacionados ao uso da terra são os mais polêmicos, pois, além de delimitar o espaço que contém recursos naturais, há dimensões sociais importantes a considerar como a questão de moradia e sobrevivência (LITTLE, 2001).

Ainda segundo Little (2001), a definição de conflito na área ambiental não se restringe somente aos impactos antropogênicos sobre a natureza, os embates referem-se a:

[...] disputas entre grupos sociais derivadas dos distintos tipos de relação que eles mantêm com o seu meio natural. $O$ conceito socioambiental engloba três dimensões básicas: o mundo biofísico e seus múltiplos ciclos naturais, o mundo humano e suas estruturas sociais, e o relacionamento dinâmico e interdependente entre esses dois mundos. (LITTLE, 2001, p. 107).

A ocupação do espaço geográfico é uma disputa que exige atenção, pois, muitas vezes envolve populações indígenas, quilombolas, ribeirinhos, caiçaras e seringueiros que desenvolvem uma economia que interage com os recursos locais como a floresta (VELASQUEZ, 2008).

Além desses grupos minoritários, há aqueles que estabelecem moradia nesses locais por conta de sua condição social. Para esse grupo, as leis que protegem os recursos naturais como uma forma de manter a qualidade de vida e a sustentabilidade do planeta representam um impedimento a um de seus direitos básicos: o direito à moradia.

Durante a elaboração do SNUC a questão das coletividades que vivem e moram nos limites territoriais das Unidades de Conservação foi delegada a um segundo plano. Por conta dessa situação, a implantação dessas unidades teve como pano de fundo o confronto entre as instituições públicas e os moradores dessas áreas protegidas (FERREIRA et al., 2001). 
Porém, apesar das polêmicas que acompanham esses conflitos e dos desgastes entre administração pública e atores, de acordo com Brito (2008):

[...] conflitos ambientais são importantes para a formulação das políticas e diretrizes que envolvem a construção da gestão e do manejo das unidades de conservação, pois, em última análise os conflitos refletem o processo histórico das lutas sociais e da transformação econômica na construção de espaços geográficos (BRITO, 2008, p.3).

Apesar dos cuidados do Poder Público e da sociedade civil, por meio da atuação de Organizações Não Governamentais (ONGs), ao formular leis de proteção a biomas e ecossistemas e do interesse de diversos setores da sociedade, percebe-se que um grupo de atores teve sua condição e direitos relegados a um segundo plano.

O Parque Tizo está inserido numa área com cerca de $1.500 .000 \mathrm{~m}^{2}$ (um milhão e quinhentos mil metros quadrados), um grande remanescente da Mata Atlântica. Antes do parque existia uma fazenda no local. Na década de 1940 começou a supressão vegetal, por conta do processo de expansão da cidade de São Paulo que continuou pelos anos seguintes, fragmentando a mata existente na região (SECRETARIA DO MEIO AMBIENTE, 2012).

De acordo com Costa (2006), a ocupação irregular na antiga fazenda começou na década de 1970 com a formação da Vila Nova Esperança e seguiu pelos anos seguintes com o adensamento dessa população.

Nos anos de 1980 surgiram os aterros legais oriundos da obra do trecho sul do Rodoanel e aterros ilegais que impactaram as lagoas da fazenda e em 2001, toda a área foi adquirida pela Companhia de Desenvolvimento Habitacional e Urbano (CDHU), que tinha a intenção de implantar um entreposto atacadista no local. Partes dessas glebas foram desmembradas por conta do Rodoanel. Em 2002, cerca de 2.000 famílias decidiram ocupar irregularmente o interior da antiga fazenda, porém, a reintegração da área invadida foi concedida pela justiça e efetivada pela CDHU ainda naquele ano. Esse fato fez com que os moradores do entorno da área se mobilizassem para a proteção do fragmento e seus serviços ambientais, porém, perceberam que o Estado tencionava prosseguir com a implantação do complexo de distribuição e abastecimento de mercadorias (SECRETARIA DE MEIO AMBIENTE, 2012).

Ciente de que esse projeto promoveria a perda da vegetação somada a um conjunto de modificações sócio-espaciais da região, a comunidade organizou uma nova mobilização com abaixo-assinados e atos públicos, em prol da preservação da mata da Fazenda Tizo (COSTA, 2006).

Foram acionados o Ministério Público e vários órgãos da administração estadual e prefeituras para que o projeto de implantação do centro de abastecimento não fosse concretizado. Em 2003, esse projeto foi arquivado devido a problemas de licenciamento ambiental. A partir de então, deu-se início a uma campanha para a criação do parque, coordenada pelas associações de amigos do bairro e escolas (SECRETARIA DO MEIO AMBIENTE, 2012). Nesse mesmo ano, foi proposto pelo Ministério Público do Estado de São Paulo, uma Ação Civil Pública contra o Estado de São Paulo, Companhia de Desenvolvimento Habitacional e Urbano do Estado de São Paulo (CDHU) e a Companhia de Desenvolvimento Agrícola de São Paulo (CODASP), que resultou em uma sentença proferida em 2004, determinando a adoção de 
medidas para a preservação da vegetação e dos mananciais, a recuperação das áreas degradadas e impedindo o parcelamento da área, o que contribuiu para a criação do parque (COSTA, 2006).

Após a sentença, foram organizados vários encontros regionais para a discussão sobre a preservação daquele espaço envolvendo os moradores próximos à Fazenda Tizo e prefeituras vizinhas. Três anos após a propositura da Ação Civil Pública, em 27 de março de 2006 foi editado o Decreto Estadual 50.597, que criou o Parque Tizo. De acordo com esse decreto, o parque abrange uma área de $1.300 .000 \mathrm{~m}^{2}$ (um milhão e trezentos mil metros quadrados) pertencente a cinco municípios do Estado de São Paulo: Cotia, Embu das Artes, Osasco, São Paulo e Taboão da Serra, sendo que o mesmo está segmentado pelo Rodoanel Mário Covas (SECRETARIA DO MEIO AMBIENTE, 2012).

Os principais objetivos da criação do parque consistem na:

[...] preservação do fragmento remanescente de Mata Atlântica que ali se encontra e o incentivo à pesquisa e a sustentabilidade através de práticas de educação ambiental voltada à conscientização de gestão ambiental. (SÃO PAULO, 2006a, p.01).

Após o decreto, a Resolução 30, de 30/06/2006, da Secretaria de Meio Ambiente do Estado de São Paulo, dispôs sobre a criação do Conselho de Orientação do Parque Tizo (COTIZO), que se reúne mensalmente, com objetivo de

[...] fomentar um processo participativo para a elaboração do plano diretor do parque e promover a articulação entre órgãos públicos e entidades de ensino a fim de definir diretrizes para o manejo e conservação da área, garantindo a participação efetiva de todos os atores envolvidos na criação do parque (SÃO PAULO, 2006b).

\section{CONFLITOS SOCIOAMBIENTAIS NO PARQUE TIZO}

A relação entre população e conservação da natureza tem sido marcada por problemas de diversas ordens e magnitudes e estão no cerne da política de proteção ambiental (BRITO, 2008).

Compatibilizar as exigências de conservação com os problemas criados a partir do congelamento de um território de grandes proporções localizado em um bairro populoso, com atividades econômicas e de urbanização em expansão é uma tarefa conflituosa, dispendiosa e tecnicamente de difícil resolução (FERREIRA, 2001).

A área do Parque Tizo está inserida em uma gleba maior composta por várias matrículas pertencentes à $\mathrm{CDHU}$. O assentamento irregular Vila Nova Esperança está localizado em área limítrofe ao parque. Todas as atividades oriundas dos moradores dessa vila afetam diretamente a biota local, além de servir de incentivo para que outras invasões possam ocorrer no interior da antiga fazenda.

Diante da ameaça de grave dano ambiental à grande gleba, no ano de 2003, o Ministério Público, por meio da Promotoria do Meio Ambiente da Capital, propôs uma Ação Civil Pública, processo n. 053.03.029588-5, junto à 8a Vara da Fazenda Pública, determinando a desocupação do assentamento irregular e remoção de entulho e lixo, bem como a recuperação vegetal das áreas compreendidas pela totalidade das matrículas da gleba originariamente coberta pela Mata 
Atlântica. Houve um recurso da sentença, porém, o Tribunal de Justiça confirmou a sentença anterior. Durante o decorrer de todo o processo jurídico, o Promotor Dr. José Eduardo I. Lutti percebeu que a decisão não atentou quanto ao destino dos moradores envolvidos e diante dessa situação, esse promotor assumiu o papel de facilitador de diálogos entre os atores envolvidos na questão: o Ministério Público, o Governo do Estado e os habitantes da Vila Nova Esperança (LUTTI, 2012).

Para cumprir a decisão judicial proferida em 2004, a CDHU ofereceu atendimento habitacional às famílias disponibilizando apartamentos em Cotia e cartas de crédito para aquisição de imóveis. A reintegração de posse da área teve início efetivo em 2011 com a retirada amigável de 116 famílias, porém, de acordo com o último levantamento verificou-se que ainda há cerca de 300 famílias na área aguardando futuras decisões (COMPANHIA DE DESENVOLVIMENTO HABITACIONAL E URBANO, 2011).

Segundo o promotor, em comunicação escrita, no ano de 2011 as 116 famílias que foram retiradas do local somente saíram por conta da garantia de uma destinação adequada e digna, no caso os edifícios que se encontram no município de Cotia. Na época, mesmo com a sentença em fase de execução, o promotor aceitou a permanência dos demais ocupantes no local pelo prazo de dois anos, tempo suficiente para a CDHU (proprietária da área e ré na Ação Civil Pública) construir um conjunto habitacional no município de Taboão da Serra, na parte degradada da área que pertencia à Caixa Beneficente dos Policiais Militares e alocar os demais ocupantes do assentamento. Essa área degradada encontra-se apta a essa finalidade e serviria de contrapartida do governo estadual no novo acordo, sendo que a administração do local será transferida à Secretaria do Meio Ambiente e anexado à área do parque. O prazo ainda não se findou, porém há o cuidado com que a sentença seja cumprida sem que a população envolvida seja prejudicada. Este acordo ainda está em fase de elaboração (LUTTI, 2012).

Após a criação do Parque e do Conselho Orientador, em 2006, essas famílias foram cadastradas, totalizando cerca de 440 moradias na vila. Mesmo assim, denúncias de novas invasões foram relatadas durante as reuniões do Conselho de Orientação do Parque Tizo, e a Polícia Ambiental foi acionada várias vezes para impedir essas ocupações. Para barrar o aumento da vila, foi solicitada a instalação de gradil ao redor do parque bem como faixas de alerta, porém, por falta de recursos financeiros, essa barreira física não foi concluída (SECRETARIA DO MEIO AMBIENTE, 2010).

De acordo com a Secretaria do Meio Ambiente (2007), tanto a ligação de água como o estudo para implantação de rede de coleta de esgoto foram solicitadas à Companhia de Saneamento Básico do Estado de São Paulo (SABESP).

Além da vila, há aterros legais e ilegais no parque que ameaçam a integridade da vegetação desde a década dos anos 80 . Os resíduos das obras do trecho sul do Rodoanel fazem parte destes aterros. Porém, o maior deles talvez seja o da empresa Anaconda, localizado na porção de terra que pertence ao município de Osasco, com cerca de $30.000 \mathrm{~m}^{2}$ da área do parque (SECRETARIA DE MEIO AMBIENTE, 2012).

Atualmente, está sendo monitorado pela própria empresa com estações de controle de gases e de chorume, o que garante uma melhoria na qualidade ambiental da região. 
Vários impactos ambientais foram provocados pelas atividades humanas no remanescente fragmentado e que afetaram, principalmente, o Parque Tizo. Pode se elencar o lançamento de esgoto in natura em plena mata e a disposição do lixo, que afeta a biota do parque, uma vez que parte da vegetação encontra-se em processo de regeneração natural, começando a provocar efeitos indesejados na própria comunidade que iniciou esse processo, nesse caso os moradores do assentamento irregular. Além da degradação, a caça e a venda ilegal de animais silvestres e a supressão vegetal afetam diretamente a fauna e flora do parque. Vale ressaltar que a caracterização biológica da antiga Fazenda foi crucial para a criação do parque. No entanto, há várias perturbações que ameaçam o frágil equilíbrio deste ecossistema, todas relativas às atividades antrópicas locais.

Após a retirada das famílias que ainda moram na vila, se dará início à recuperação ambiental da área degradada que obedecerá às diretrizes do plano diretor elaborado pelo Conselho Orientador do parque. A constituição desse plano teve a participação das comunidades que se mobilizaram para a criação do parque e diversos outros representantes, inclusive dos moradores da Vila Nova Esperança.

O último problema a ser elencado refere-se à conceituação do próprio parque, que no momento se define como um parque urbano de lazer e uso sustentável, o que o caracteriza como um parque multifuncional, muito embora a categoria Parque seja pertencente ao grupo de Proteção Integral, o que restringe relativamente as atividades permitidas em seu interior. A proposta de uma recategorização do espaço para Área de Relevante Interesse Ecológico (ARIE), do grupo de Uso Sustentável, foi feita em reunião do Conselho (SECRETARIA DO MEIO AMBIENTE, 2008).

Essa proposta se deu devido ao fato do Parque Tizo estar localizado próximo ao Parque das Nascentes e de vários outros pequenos fragmentos florestais, o que propicia uma conectividade entre essas áreas verdes e formação de um corredor ecológico, situação prevista no SNUC. Complementando o aspecto ambiental, ainda há a questão do aporte financeiro advindo de compensações ambientais oriundas também do SNUC, o que favorece a continuação de obras de implantação no parque.

\section{CONSIDERAÇÕES FINAIS}

A criação e implantação de parques, sobretudo os localizados em perímetro urbano em processo de expansão, ensejam uma série de conflitos socioambientais, como os observados no caso do Parque Tizo. No âmbito nacional, as unidades de conservação integram o Sistema Nacional de Unidades de Conservação da Natureza (SNUC) e geralmente são criadas com a intenção de proteger os recursos naturais em uma área limitada. Juridicamente ainda não há instrumentos suficientes que facilitem o sistema de gestão das unidades federais. Na esfera estadual, em São Paulo, as áreas verdes também estão protegidas legalmente e contam com instrumentos que definem o sistema de gestão dessas áreas. Porém, mesmo com esse aparato jurídico, os diversos interesses dos atores sociais entram em colisão durante a gestão das unidades tanto na esfera federal como na estadual.

Esses interesses geram conflitos socioambientais que podem ser de uso dos recursos dessas áreas (desmatamento e tráfico de fauna, por exemplo), ocupação do espaço territorial, 
embates políticos e ampliação da malha urbana. Dentre esses conflitos, a ocupação do espaço territorial configura-se como um dos mais polêmicos, pois, envolve a questão da conservação dos recursos naturais e do uso do solo e seus aspectos econômicos e sociais.

Na história da criação do Parque Tizo, esses elementos estão bem definidos. A expansão da malha urbana ocasionou o desmatamento de um grande remanescente de Mata Atlântica que abrigava uma antiga Fazenda provocando a fragmentação da vegetação. Esse dano ambiental permitiu o assentamento irregular (Vila Nova Esperança) nas regiões limítrofes desta fazenda, ocasionando uma série de impactos socioambientais resultantes dessa atividade humana. A preocupação ambiental impulsionou a comunidade vizinha a se mobilizar para criação do parque, o que acentuou o conflito referente à ocupação ilegal existente no local. Antes da instituição do parque, o Tribunal de Justiça já havia sentenciado a reintegração de posse, solicitada em uma Ação Civil Pública formulada pelo Ministério Público, cujo promotor, autor da ação, também atuou como o facilitador de diálogos entre o governo estadual, uma vez que a CDHU é a proprietária do remanescente fragmentado. Como facilitador, o promotor conduziu a retirada de uma parte dos moradores para um espaço digno de moradia. As famílias que ainda se encontram no assentamento estão aguardando um novo acordo para remoção e transferência, cuja negociação está mais uma vez sendo conduzida pelo mesmo Promotor de Justiça. A decisão da justiça deve ser mantida, porém, a facilitação de diálogos entre as partes interessadas tomam as decisões judiciais menos frias e mais humanas no tocante ao destino das pessoas que praticaram a ocupação irregular devido à sua frágil condição econômica e social.

A mobilização para a criação do parque do Parque Tizo contou com a participação de vários atores sociais, inclusive aqueles que estão em conflito pelo uso da terra nos limites do parque, tornando-o um estudo de caso apropriado para a discussão de elementos de facilitação de diálogo em caso de conflitos socioambientais.

Com relação aos impactos ambientais constatados no Parque Tizo destacam-se aqueles decorrentes das atividades humanas no remanescente fragmentado, como o lançamento de esgoto in natura em plena mata, disposição inadequada do lixo, caça e a venda ilegal de animais silvestres e a supressão vegetal que causam degradação e impactos ambientais tanto à fauna e flora local, quanto à população do entorno.

Quanto aos conflitos socioambientais, destacam-se os relativos ao uso dos recursos naturais da área, os embates políticos, a ampliação da malha urbana e a ocupação territorial descontrolada. Este último de maior relevância visto às interferências com os demais e a manutenção do equilíbrio entre conservação dos recursos naturais e uso e ocupação do solo por assentamentos urbanos e infraestrutura.

Com relação à negociação desses conflitos socioambientais ressalta-se o papel do poder público, por meio de agente da Promotoria de Meio Ambiente do Estado de São Paulo, como responsável pela facilitação do diálogo entre partes interessadas e adoção de efetivas ações positivas para a população afetada. Nesse quesito, a atuação do Promotor Público como facilitador do diálogo entre as partes envolvidas tornou-se essencial para fazer colocar em prática a decisão judicial de modo a atender as necessidades daqueles que invadiram a área e o próprio parque.

Do ponto de vista de proteção da unidade de conservação, com relação ao conflito pelo uso das terras, uma sentença judicial foi proferida e é necessário que seja cumprida, com a 
retirada das famílias que fazem parte do assentamento ilegal. Agrega-se a proposta de recategorização do parque como um possível caminho para sua proteção efetiva e para formação de um mosaico na malha urbana da região, ampliando a gama de serviços ambientais prestados à comunidade do entorno.

A proposta para recategorização da área, onde o parque urbano passa a ser uma Área de Relevante Interesse Ecológico parece ser o caminho para a liberação de recursos financeiros que serão utilizados numa proteção mais efetiva do espaço, além de permitir a formação de um mosaico de vegetação na malha urbana daquela região, o que será um ganho ambiental valioso para a população de todos os municípios que formam o parque.

\section{AGRADECIMENTOS}

Agradecemos à gestora Ana Lucia P. de Faria Burjato, da Secretaria de Meio Ambiente do Estado de São Paulo (SMA), por fornecer o histórico do Parque e os dados do Plano Diretor.

Agradecemos ao DD. Promotor de Justiça Dr. José Eduardo Ismael Lutti, pela entrevista

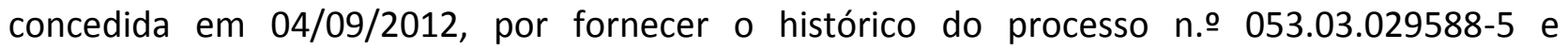
informações sobre as reuniões com os moradores da vila Nova Esperança.

\section{REFERÊNCIAS}

1. BRASIL. Constituição (1988). Constituição da República Federativa do Brasil: promulgada em 5 de outubro de 1988. Disponível em: <http://www.planalto.gov.br/ccivil_03/Constituicao /Constitui\%C3\%A7ao.htm>. Acesso em: 10 nov. 2009.

2. BRASIL. Lei n. 99985 , de 18 de julho de 2000. Regulamenta o art. 225 , § 1., incisos I, II, III e VII da Constituição Federal, institui o Sistema Nacional de Unidades de Conservação da Natureza e dá outras providências. Diário Oficial da União, Brasília, 19 jul 2000.

3. BRITO, D. M. Conflitos em unidades de conservação, PRACS: Revista Eletronica de Humanidades do Curso de Ciências Sociais da UNIFAP, Amapá, n.1, p. 1-12,dez. 2008. Disponível em <http://periodicos.unifap.br/index.php/pracs/article/viewArticle/10>. Acesso em 30 abr. 2012.

4. COMPANHIA DE DESENVOLVIMENTO HABITACIONAL E URBANO. Secretaria da Habitação. Governo do Estado de São Paulo. Nota à Folha de São Paulo, São Paulo: CDHU, 26 abr 2011.

5. COSTA, R. Impactos sobre remanescentes de florestas de Mata Atlântica na Zona Oeste da São Paulo: um estudo de caso da mata da Fazenda Tizo. 2006, 211 f. Dissertação (Mestrado em Geografia Física) - Universidade de São Paulo, São Paulo, 2006.

6. FERREIRA, L. C. et al. Conflitos sociais em áreas protegidas no Brasil: moradores, instituições e ONGs no Vale do Ribeira e litoral sul,sp. Idéias, São Paulo, v.1, n. 8 , p.115-150, 2001.

7. GUERRA, M. F. Conflitos ambientais no Parque Natural Municipal de Grumari. Revista Rio de Janeiro, Rio de Janeiro, n.16-17, p.115-130, maio/dez. 2005.

8. INSTITUTO FLORESTAL. Secretaria de Meio Ambiente, Governo do Estado de São Paulo. Consulta geral homepage. Disponível em: <http://www.iflorestal.sp.gov.br/areas_protegidas /index.asp>. Acesso em: 05 maio 2012. 
9. LITTLE, P. E. Os conflitos ambientais: um campo de estudo e de ação política. In: BURSZTYN,M. A difícil sustentabilidade: política energética e conflitos ambientais. Rio de Janeiro: Garamond Ltda, 2001, p.107-122.

10. LUTTI, J.E.I. Elucidação sobre o parque Tizo [mensagem pessoal]. Mensagem recebida por <paulina_arce@biologa.bio.br> em: 04 set 2012.

11. SÃO PAULO. (Estado). Decreto no 57.458, de 25 de outubro de 2011. Autoriza a Fazenda do Estado a receber da Companhia de Desenvolvimento Habitacional e Urbano do Estado de São Paulo - CDHU, mediante permissão de uso a título precário, gratuito e por prazo indeterminado, imóveis que especifica, situados nos Municípios de São Paulo, Cotia e Osasco. Diário Oficial do Estado, São Paulo, 25 out. 2011.

12. SÃO PAULO (Estado). Decreto Estadual n.o 50.597, de 27 de março de 2006. Cria o Parque Urbano de Conservação Ambiental e Lazer em área localizada nos Município de São Paulo, Cotia e Osasco e dá providências correlatas. Diário Oficial do Estado, São Paulo, 28 mar $2006 a$.

13. Secretaria de Estado do Meio Ambiente. Resolução SMA 30, de 30 de junho de 2006. Diário Oficial do Estado, São Paulo, 01 de jul 2006b.

14. SECRETARIA DO MEIO AMBIENTE. Conselho Orientador do Parque Tizo. Ata da quinta reunião realizada no dia 24 de abril de 2007, p.1-2.

15. Conselho Orientador do Parque Tizo. Ata da décima-segunda realizada no dia 24 de setembro de 2008 , p. 1-2.

16. Conselho Orientador do Parque Tizo. Ata da décima-nona reunião realizada no dia 08 de junho de 2010, p.1-2.

17. _. Plano Diretor e diretrizes de projeto para o Parque Tizo. 3. ed. São Paulo: Impressa Oficial do Estado de São Paulo, 2012, 116p.

18. SIMON, A. Conflitos na conservação da natureza: o caso do parque estadual da serra da tiririca. In: ENCONTRO DA ASSOCIAÇÃO NACIONAL DE PÓS-GRADUAÇÃO E PESQUISA EM MEIO AMBIENTE E SOCIEDADE, 2., 2004. Anais... Indaiatuba, ANPPAS, 2004.

19. VELASQUEZ, C. Áreas Protegidas. In: INSTITUTO SOCIOAMBIENTAL. Almanaque Brasil Socioambiental. São Paulo: Instituto Socioambiental, 2008. p. 261-269. 